\title{
EL PODER JUDICIAL PERUANO COMO OBJETO DE ESTUDIO PARA LA CALIDAD DE LA DEMOCRACIA Y ADMINISTRACIÓN DE JUSTICIA EN EL PERÚ. VENTAJAS Y DIFICULTADES
}

\begin{abstract}
SERGIO SALAS VILLALOBOS ${ }^{* *}$
Si el Poder Judicial es un instrumento de Poder, ¿Quién es el titular del poder del Poder Judicial?

"The Rule of Law. As Guillermo O'Donell explains, the rule of law means that all citizens are equal before de the law, and that the laws themselves are clear, publicly known, universal, stable, non-retrocative, and fairly and consistently applied to all citizens by an independent judiciary. These characteristics are fundamental for any civil order and basic requirement for democratic consolidation..."1
\end{abstract}

\section{Resumen}

El presente trabajo formula reflexiones sobre el modelo del sistema judicial peruano, como integrante de un sistema democrático de mayor espectro, el cual necesita bases sólidas para su institucionalización. Se abordan las debilidades del sistema, aún vigentes pese a los esfuerzos personales de algunos jueces conductores de la gestión a lo largo de los últimos años. $\mathrm{Si}$ bien en otros ensayos ya hemos desarrollado la técnica de la identificación de los sistemas judiciales, no obstante, consideramos que el propósito de este trabajo, al estar orientado a una visión política del sistema judicial en el Perú, exige ahora una definición de aquellos dentro del campo político.

Palabras clave: Sistema judicial - Poder Judicial - Jueces - Democracia Ideologías - Doctrina judicial - Carrera judicial.

\begin{abstract}
This brief provides thoughts on the model of the Peruvian Judicial system, as a member of a democratic system of a wider spectrurn that requires solid bases for its institutionalization. We address the weaknesses of the system
\end{abstract}

* Ponencia del autor en el Taller de Investigación comparada: Calidad de la democracia y administración de justicia en América Latina, realizado en el Hotel Boulevard, 23 y 24 de Mayo de 2013. Miraflores, Perú. Projusticia.

** Ex Presidente de la Corte Superior de Justicia de Lima 2001 - 2002. Ex Juez Provisional de la Corte Suprema de la República - Poder Judicial del Perú. Especialista en Política Jurisdiccional y Derecho Judicial, Profesor universitario.

1 MorlinO, Leonardo and DiAmOND, Larry. Assessing the Quality of Democracy. The Johns Hopkins University Press and the National Endowment for Democracy. Baltimore, Maryland. United States of America. 2005. pg. xiv.

"La Regla de la Ley. Como lo explica Guillermo O’Donell, la regla de la Ley significa que todos los ciudadanos son iguales ante la ley, y las leyes por si mismas deben ser claras, de conocimiento público, universal, estables, sin efecto retroactivo y justas y efectivamente aplicadas a todos los ciudadanos por un Poder Judicial independiente. Estas características son fundamentales para cualquier orden civil y requisitos básicos para la consolidación democrática...". 
Sergio Salas Villalobos - El Poder Judicial Peruano como objeto de estudio para la calidad de la democracia y administración de justicia en el Perú. Ventajas y dificultades

which continues to exist despite the personal efforts of some judges directing this process over the last few years. Although we have developed the method to identify judicial systems in other protocols, we believe that since it aims to provide a political view of the judicial system in Peru, the purpose of this paper now requires their definition in a political context.

Key words: Judicial System - Judges - Democracy - Ideologies - Legal Doctrine - Judicial Career.

\section{Sumario}

I.- A modo de introducción. II.- Modelos de los sistemas judiciales. III.Poder Judicial como garantía de democracia. Elementos y sus componentes. 1.-Composición orgánica. 2.- Ideologías como Doctrina judicial. IV.- A manera de conclusión.

\section{A MODO DE INTRODUCCIÓN}

Es usual que en el sistema judicial peruano, nos encontremos con una serie de acontecimientos singulares que son el reflejo de la falta de democratización del Poder Judicial y de la histórica intervención política que no le permitió desarrollarse como organización y mucho menos como poder del Estado.

Esta falta de democratización parece desvanecerse o atenuarse recién en el presente siglo XXI, en donde los nuevos modelos sociales y constitucionales, exigen a los jueces una presencia mayormente participativa, si bien autónoma, no obstante sin perder la perspectiva de dichos aspectos sociales imperantes. Por lo tanto, una percepción errada por parte de la sociedad respecto del autogobierno de los jueces, puede ocasionar desastrosas consecuencias en cuanto al nivel de aceptación del sistema judicial y, con ello, el retardo en su ansiada evolución para la estabilización social y democrática del país.

Siendo ello así, los jueces están comprometidos no solo para saber gobernarse bien, sino para propiciar cambios sistémicos sustanciales con miras a su desarrollo institucional. El sistema judicial, debe ser estable, confiable, bien organizado, pero sobre todo, auténticamente democrático en su composición y en la forma de impartir justicia.

Estas reflexiones formales pueden entenderse describiendo algunos de los mencionados acontecimientos singulares, como por ejemplo la creación de órganos jurisdiccionales como parte del programa de descarga procesal sin medición de indicadores, o la selección de jueces a plazas provisionales que 
Sergio Salas Villalobos - El Poder Judicial Peruano como objeto de estudio para la calidad de la democracia y administración de justicia en el Perú. Ventajas y dificultades

no son de la especialidad para resolver casos complejos o jurídicamente especializados, o la desatención del juez de su despacho para priorizar $\mathrm{su}$ proceso de ratificación; entre otros. Son innumerables los tipos de acontecimientos que los usuarios del Poder Judicial peruano sufrimos que, por cierto, no son extraños en los demás sistemas judiciales de la región latinoamericana. Aunque no parezca creíble, el sistema peruano se encuentra más consolidado que los de los demás países, a excepción de Brasil, Costa Rica y Chile, en ese orden; lo que no debería necesariamente darnos orgullo, ya que aún no llegamos al nivel mínimo de confiabilidad democrático-social.

Las siguientes son algunas reflexiones sobre el modelo del sistema judicial peruano, como integrante de un sistema democrático de mayor espectro, el cual necesita bases sólidas para su institucionalización. Por tanto, insistiremos en las debilidades del sistema, las cuales incomprensiblemente se han mantenido vigentes pese a los esfuerzos personales de algunos jueces conductores de la gestión a lo largo de los últimos años. Para ello, tendremos que ser necesariamente críticos, pero con respeto tanto a la institución judicial como a sus componentes. La intención, en todo caso, es promover sino provocar la generación de nuevos líderes para que "prenda" la chispa de la nueva ideología judicial y las acciones realmente necesarias y positivas de todo el sistema.

\section{MODELOS DE LOS SISTEMAS JUDICIALES}

Si bien en otros ensayos ya hemos desarrollado la técnica de la identificación de los sistemas judiciales, no obstante, consideramos que el propósito de este trabajo, al estar orientado a una visión política del sistema judicial en el Perú, exige ahora una definición de aquellos dentro del campo político.

Así, y como nuevamente reiteramos la descripción de GARCía BELAÚNDE, los modelos de los sistemas judiciales en las sociedades occidentales con prácticas constitucionales y democráticas, son de tres tipos: Parlamentarista, Corporativo é Institucionalista ${ }^{2}$. Debemos, no obstante, resaltar que nos hemos permitido adaptar esta clasificación del maestro GARCíA BELAÚNDE, de acuerdo a la necesidad de su adecuación dentro de la perspectiva del estudio de los mismos para su ejercicio práctico. En esa dimensión, el modelo Parlamentarista o europeo ${ }^{3}$, se caracteriza por la presencia activa tanto del

2 García Belaúnde, Domingo. «Problemas sobre el gobierno y la Administración del Poder Judicial». Publicado en La Justicia Mexicana hacia el siglo XXI por la Universidad Nacional Autónoma de México y el Senado de la República LVI Legislatura.

3 También llamado político. 
Sergio Salas Villalobos - El Poder Judicial Peruano como objeto de estudio para la calidad de la democracia y administración de justicia en el Perú. Ventajas y dificultades

Poder Ejecutivo y del Legislativo para el óptimo desarrollo del Judicial como componente del Estado, y en el entendimiento que éste sirve al ciudadano. Por lo tanto, la exigencia de la sociedad hacia el Estado en temas de justicia, exime al juez de dirigir la gestión de administración, concentrándose única y exclusivamente en su función jurisdiccional pura. El Poder político participa en su organización y administración de buenas prácticas públicas y el Judicial en su autogobierno. Nadie se atrevería a sostener que en este modelo, la conducta del Estado implica intervención política en el judicial; como sí lo sería en los sistemas latinoamericanos. El término reforma judicial, es inexistente en este modelo debido a su sostenimiento permanente.

En cuanto a la dimensión del sistema corporativo o norteamericano, como lo indica su nominación, es el reflejo perfecto del funcionamiento de un solo cuerpo autónomo e independiente: el Judicial. En los Estados democráticos, solo los Estados Unidos de Norteamérica continúa con el modelo de separación de poderes original de la Revolución Francesa ${ }^{4}$. Por tanto su manejo es totalmente propio. La administración depende de su propio brazo técnico ${ }^{5}$, el cual le provee de los insumos técnicos y tecnológicos de avanzada para optimizar su perfil organizacional. Además, desarrolla la función formativa de sus componentes, esto es que capacita y entrena a los futuros funcionarios judiciales de las Cortes Estatales, de manera que para laborar en ellas, se requiere obligatoriamente de una licenciatura de la institución académica. Es oportuno señalar, que los formadores y ejecutivos del Centro, son ex magistrados, lo que indica el amplio desarrollo ideológico y de liderazgo de sus componentes principales: los jueces. $\mathrm{Al}$ igual que en el modelo europeo, en el corporativo el término reforma judicial es inexistente, y los jueces se concentran en una única función, la jurisdiccional.

Por último, el sistema institucionalista o latinoamericano; el menos apropiado de todos. Estando vigente en los países hispanos, el sistema de Estado Constitucional en reemplazo del Estado de Derecho clásico, el principal componente del mismo es la difusión de órganos constitucionales autónomos, con funciones propias y exclusivas, que no dependen de ningún poder del Estado, pero que inciden en sus funciones de manera indirecta. Los Tribunales Constitucionales, Consejos de la Magistratura, Procuraduría Pública -en el caso de Colombia-, el Ministerio Público, los órganos electorales, etcétera, desarrollan sus funciones de manera autónoma. Sin embargo, sus funciones

\footnotetext{
4 Aún cuando el jurista, constitucionalista y político peruano Javier Valle Riestra, insista en la permanencia de dicho modelo en el Perú, el mismo ha sido paulatinamente desplazado por el del Estado Constitucional; el cual agrega al escenario de los poderes del Estado, el de los llamados órganos constitucionales autónomos, los que inciden en las funciones de aquellos.

5 El Nacional Center for State Courts, con sede en Williamsburg, Virginia.
} 
Sergio Salas Villalobos - El Poder Judicial Peruano como objeto de estudio para la calidad de la democracia y administración de justicia en el Perú. Ventajas y dificultades

se entrelazan, por ejemplo en cuanto al nombramiento de jueces, fiscales, sanciones a los mismos, declaración de inconstitucionalidad de leyes a través del control concentrado, lo que altera las políticas orgánicas de los poderes públicos, etc. En el Perú, se aprecian muchas competencias del Tribunal Constitucional que han afectado de manera directa las funciones de los tres poderes del Estado 6 .

Bajo este panorama, es claro que la conducción de los Poderes Judiciales latinoamericanos es por demás compleja. Es usual el conflicto presente entre estas instituciones, como el caso de Argentina y Ecuador entre sus Poderes Judiciales y los Consejos de la Magistratura; mientras que en el primer caso el Consejo es sumamente influyente, en el segundo es todo lo contrario ${ }^{7}$. Esto exige que los jueces se preocupen, por ende, de dos misiones: su propia administración y la función jurisdiccional propiamente dicha, a diferencia de los modelos europeo y corporativo. Doble tarea que implica descuidar ambas. De ahí la premisa que los jueces en latinoamérica no pueden conducir sus procesos de reforma. Por lo demás, como también lo hemos tratado en otros ensayos, en el Perú al menos, no han existido procesos técnicos de reformas judiciales ${ }^{8}$.

De lo expuesto, no queda duda que el modelo institucionalista o latinoamericano, es el menos apropiado para estructurar eficientemente todos sus sistemas judiciales y, por ende, se vuelve incierta la premisa de O'DONELL para la consolidación democrática de sus Estados. La única alternativa es la formación y reforzamiento de auténticos liderazgos judiciales, de fondo y no de forma, es decir de ideologías y acciones, más no de ejercicios de cargos naturales de función. Intentar acoplar el modelo parlamentarista o europeo, significaría estar bajo la sombra de los regímenes autocráticos del poder político y sería suicida para nuestros sistemas.

6 El caso de la Ley Wolfenson; la contienda competencial entre el Poder Judicial y el Poder Ejecutivo por el tema presupuestario; los casos de la Cosa Juzgada Constitucional y anulación de Sentencias de los órganos jurisdiccionales en el tema de las máquinas tragamonedas y casinos de juego; recientemente la anulación por el Tribunal Constitucional respecto de la Acción de Cumplimiento de homologación de remuneraciones de los jueces contra el Ministerio de Economía; entre otros.

7 Para los efectos de este estudio, se deja constancia que tal apreciación es de índole sistémico, al margen de la influencia de presión que ejerza el actual mandatario de la nación ecuatoriana.

8 De acuerdo al Diccionario de la Real Academia Española, una acepción de reforma es: Aquello que se propone, proyecta o ejecuta como innovación o mejora en algo. Esto, es asimilado en la cultura organizacional con el mismo concepto, por lo tanto, se requiere de propuestas, proyectos y ejecución de ellos para mejorar un sistema. En el Perú, ninguno de estos componentes y acciones, se ha realizado; solo lo intentó el movimiento de 1996. Antes de ello, los llamados procesos de reformas judiciales apuntaron solo a cambios de jueces por el poder político (reformas republicanas). La última fue en el año 1992, con el llamado autgolpe del ex presidente Fujimori. Por ello, uno de los autores de la reforma del 96, Ibazeta Marino, proponía una reforma traumática; esto es, la demolición total del sistema y su reemplazo por otro. Sin embargo, este tipo de reformas es inviable si no se cuenta con un modelo ya estructurado, cosa que no tuvo aquel proceso. 
Sergio Salas Villalobos - El Poder Judicial Peruano como objeto de estudio para la calidad de la democracia y administración de justicia en el Perú. Ventajas y dificultades

\section{PODER JUDICIAL COMO GARANTÍA DE DEMOCRACIA. ELEMENTOS Y SUS COMPONENTES}

Habiendo analizado sucintamente el panorama de diseños de los sistemas judiciales, corresponde identificar los elementos que puedan servir para la identificación estructural vigente y si ella es garantía del ejercicio democrático en el Perú; siempre bajo la perspectiva de O'DONELL.

En tal sentido, advertimos dos elementos sustanciales: la composición orgánica u organizacional del Poder Judicial y el desarrollo de ideologías como doctrina judicial.

Si bien es cierto, la perspectiva organizacional abarca un complejo entretejido de sub-sistemas, estos no serán tratados en este estudio. Lo trascendente es analizar sus componentes principales dentro de los cuales se desarrollan tales sub-sistemas. Tales componentes están comprendidos por la identificación de los órganos para el funcionamiento organizacional, sus recursos y los métodos de selección de los operadores judiciales, incluyendo lo derivado respecto de su control como integrantes de la organización.

El objetivo de hacer esta identificación es desterrar el mito de que el Poder Judicial debe adquirir legitimidad plena, por su sola condición de poder del Estado. Es decir, que la sociedad debe legitimar al Poder Judicial per se, y por ende, los otros componentes estatales deberán acatar esta legitimidad ciudadana, como base de fortalecimiento democrático. La aprobación per se, en consecuencia no requiere de mayor esfuerzo institucional ni funcional. Basta declarar el principio de autonomía del Poder Judicial como una garantía constitucional lírica, para que este quede legitimado automáticamente. Esta creencia, lamentablemente ha sido empleada como doctrina judicial durante el siglo veinte, en el que el juez se declaraba apolítico socialmente, sin intervenir siquiera en políticas propias del Poder Judicial'; factor indispensable en un modelo corporativo como lo era el peruano en esa época.

\section{Composición orgánica}

Es claro que se requiere de un alto nivel orgánico u organizacional, para adecuar la legitimidad en base a respuestas confiables, justas, adecuadas y oportunas del aparato jurisdiccional. El Poder Judicial debe ser eficiente

\footnotetext{
9 Extensamente lo trata Luis Pásara en su ya clásica obra Jueces, Justicia y Poder en el Perú. Centro de Estudios de Derecho y Sociedad. Perú. 1982.
} 
Sergio Salas Villalobos - El Poder Judicial Peruano como objeto de estudio para la calidad de la democracia y administración de justicia en el Perú. Ventajas y dificultades

como organización -y por ende sus componentes- para adquirir respeto y legitimidad ciudadana. Solo de esa manera, el principio de autonomía adquiere vigor y vigencia. Dejará de ser una declaración principista para tornarse un principio efectivo, concreto y material. Por lo tanto, el poder del Poder Judicial será válidamente ejercido a través de si mismo y ya no per se.

Ahora bien, este elemento a su vez requiere de ciertos componentes concretos, a través de los cuales se logrará la efectividad en el diseño de la organización. Ella está compuesta de medios, los cuales están identificados como todos aquellos que participan en el desarrollo práctico de la institución; y pueden ser materiales y humanos.

\section{Órganos}

El primer componenteclaramenteidentificable, son los órganos institucionales. Se entiende por órganos, a los entes que forman una unidad estructural encargada de la función determinada de una Organización matriz. Así, a nivel organizacional podemos identificar y diferenciar los de gobierno, gestión, administración y gerencia.

Estos componentes organizacionales son distintos y tienen diferentes roles. Sin embargo, la estructura orgánica vigente los funde en uno solo: órganos de gestión prescindiendo de la identificación básica y necesaria de los demás ${ }^{10}$. La justificación de un diseño adecuado no es antojadiza; es propia de cualquier institución que se precie de desarrollar fines y objetivos claramente definidos por la propia naturaleza de su constitución. No se puede mantener la casa si la tenemos desordenada, si la distribución de sus ambientes no son los funcionalmente necesarios; no podemos dormir en el baño, ni cocinar en las habitaciones. Lo mismo sucede en las instituciones organizacionales.

Por ello, los órganos de gobierno deben tener clara que su función es la de adoptar decisiones para el destino institucional, cual es la identificación de las políticas necesarias a desarrollar por los órganos ejecutores. En el caso del Poder Judicial, la identificación clara y precisa de políticas institucionales para ser propuestas como políticas de Estado en materia de justicia. La adecuada lectura del comportamiento de los conflictos sociales sometidos a la tutela jurisdiccional por actos propiciados por el propio Estado a través

\footnotetext{
${ }_{10}$ Ley Orgánica del Poder Judicial. Sección Segunda. Organización del Poder Judicial. Titulo II. Órganos de Gestión.
} 
Sergio Salas Villalobos - El Poder Judicial Peruano como objeto de estudio para la calidad de la democracia y administración de justicia en el Perú. Ventajas y dificultades

de la administración pública o por falta de políticas de prevención social del gobierno central; base de la seguridad ciudadana por cierto.

Para graficar esta idea, tenemos que en los ansiados Mensajes a la Nación por el Presidente de la República cada veintiocho de julio, escasamente se pronuncia sobre actos del gobierno central en materia de justicia. La justificación de ello, es que no le corresponde. Debería corresponderle al propio Poder Judicial. Sin embargo, en los mensajes de aperturas de años judiciales solemos escuchar el logro de la meta de producción jurisdiccional sin relevar la productividad, factor preeminente sobre la primera para lograr la eficiencia de acuerdo a los conceptos organizacionales. No se mencionan perspectivas basadas en análisis sobre qué debe hacer el Poder Judicial respecto, por ejemplo, de la ineficiencia de la administración pública que deriva en acciones contencioso administrativas. $\mathrm{O}$ la creciente demanda de tutela por actos delictivos propios de la competencia penal. Mucho menos de la falta de atención del Estado en temas de violencia familiar o desamparo de niños y adolescentes. Todos estos análisis como políticas de Estado en materia de justicia, pueden hacerse si es que el propio Poder Judicial, por intermedio de sus órganos de Gobierno, pueda dar lectura adecuada a sus estadísticas de demanda de acceso a la justicia ${ }^{11}$.

Por su lado, los demás órganos, serán exclusivamente de acción derivada; esto es, que deberán realizar los actos necesarios para tornar prácticas las políticas institucionales identificadas y definidas por el órgano de gobierno. Así, los órganos de gestión o Consejos Ejecutivos, serán el paralelo de los Directorios de las sociedades civiles o mercantiles. Toda organización institucional, tiene un cuerpo de directivos que se encarga de orientar las normas necesarias para impartir órdenes, las que al ejecutarse por otros órganos técnicos, logran la materialización de aquellas políticas. Su labor, en consecuencia, es directiva y de supervisión de los métodos empleados por los órganos técnicos.

A su turno, los órganos técnicos propiamente dichos se encargarán separadamente de la administración y el gerenciamiento. La primera función, se dedicará a la satisfacción del uso de los recursos presupuestarios ordinarios. El presupuesto público está destinado a los gastos corrientes y ordinarios:

\footnotetext{
${ }^{11}$ La falta de lectura estadística para fines de planeamiento estratégico, se deriva de la falta de la información que los órganos de gestión gerencial debe facilitar al órgano de gobierno. El motivo es obvio; no es falta de acceso a la información, es fundamentalmente, mantener el empoderamiento del Poder Judicial manteniendo oculta la misma. Finalmente, el poder lo tiene quien posee la información; solo así, puede solucionar la problemática que dicho poder puede crear, tornándose indispensable.
} 
Sergio Salas Villalobos - El Poder Judicial Peruano como objeto de estudio para la calidad de la democracia y administración de justicia en el Perú. Ventajas y dificultades

planillas de sueldos y salarios, servicios públicos, mantenimiento común, obligaciones previsionales y tributarias; etc. En consecuencia, sostener que para llevar a cabo un proceso de reforma, se requiere incrementar el presupuesto del Poder Judicial, no solo es una falacia sino un mito. El presupuesto público no está destinado a fines de inversión. Así de simple. Sostener lo contrario implicaría que el Poder Judicial requerirá entonces la asignación del cien por ciento del presupuesto público del Estado para llevar a cabo el proceso de reforma. Nada más absurdo. Por su parte, las funciones de gerenciamiento si deberán identificarse con aptitudes técnicas más especializadas para aplicar procesos y procedimientos ejecutables de manera práctica. Son los encargados de desarrollar, planificar y ejecutar proyectos. Implementar las formas y mecanismos propios de orden logístico, técnico y tecnológico. La auténtica modernización del sistema, parte de los llamados servicios judiciales ${ }^{12}$; los cuales deben ser identificados por entes gerenciales altamente calificados. La tecnología y modernidad puesta al servicio del sistema judicial.

\section{Recursos}

Otro componente importante del elemento de composición orgánica, son los recursos económicos y materiales. Ninguna organización puede sobrevivir sin recursos económicos; aún, aquellas que no tengan fines de lucro. Un recurso es aquello que se puede usar para producir otro bien. En la lista de los recursos económicos, además de los naturales se incluye el trabajo, el capital (maquinaria, edificios y otros recursos creados por el hombre) y el capital humano. Un recurso es escaso cuando las cantidades de que se disponen no son suficientes para satisfacer las necesidades productivas ${ }^{13}$. Adecuando esta definición macroeconómica diremos que el Poder Judicial produce un bien -la Justicia a través del reconocimiento de los derechos- a través de un servicio judicial. Por tanto, el objeto de la producción de los sistemas judiciales no son las resoluciones que se miden por frías e intrascendentes estadísticas sin criterios de planificación. El objeto de la producción son los servicios judiciales.

Las reglas macroeconómicas, nos indican que es imprescindible determinar si tales servicios son de orden público o privado; ello, a efectos de establecer

\footnotetext{
12 Servicios judiciales son todos aquellos que son accesorios y complementarios para la labor jurisdiccional y sin los cuales el proceso en sí mismo, no tendría materialización práctica. Se caracterizan por su cualidad de ordenar los elementos derivados del proceso y que son necesarios para su conducción. Ejemplo, expediente digital, certificados digitales para exhortos, antecedentes penales y judiciales, registro biométrico y digital, etc. Ver el link: http://www.serjudicial.com/ que ilustra el servicio de información judicial en Colombia a través de una suscripción en INTERNET y que no es administrada por su Poder Judicial.

13 KRUGMAN, Paul; WeLLS, Robin. «Macroeconomía: introducción a la economía». Versión española traducida por Gotzone Pérez Apilanez. Editorial Reverté S.A. Barcelona, España. 2006. pg. 6.
} 
Sergio Salas Villalobos - El Poder Judicial Peruano como objeto de estudio para la calidad de la democracia y administración de justicia en el Perú. Ventajas y dificultades

sus costos y eficiencias en torno a una serie de externalidades que se presentan en su proceso de prestación. Es decir, se debe determinar quién asume el costo y el desarrollo práctico de tales servicios judiciales. Estudios contemporáneos en materia de gestión pública, vienen recomendando con mayor convencimiento, que la justicia (sus servicios) en algunos casos es un bien privado y en otros uno público, por lo que no tiene sentido alguno otorgarle al Estado el absoluto monopolio del servicio de justicia, ni asignar sobre todo él, un derecho de propiedad pública ${ }^{14}$.

Con esto, se quiebran los mitos existentes sobre las bondades de la intervención estatal que data de tiempos inmemoriales que creen que el servicio de justicia debe ser de propiedad pública é íntegramente brindado por el Estado ${ }^{15}$.

Entendido esto así, surge la gran pregunta: ¿Cómo se provee de recursos económicos al Poder Judicial para lograr la producción de los servicios judiciales que ofrece?

La respuesta trillada ha sido: a través del Presupuesto público y de los ingresos propios que están representadas por el noventa por ciento que se recaba a través de las tasas judiciales.

Al determinarse la naturaleza de la propiedad de los servicios judiciales en un Estado democrático moderno y de acuerdo a lo expuesto, la práctica nos dice que esos ingresos totales, aún siguen siendo insuficientes para invertir en organizar adecuadamente el sistema judicial. Frente a ello, existe igualmente, una uniforme resistencia a incrementar los recursos económicos a través de dichos medios. Los presupuestos públicos son limitados y se pierden esfuerzos intentando convencer a los Poderes Ejecutivo y Legislativo para incrementar el presupuesto y las partidas arancelarias extraordinarias. Las intensas visitas de los titulares del pliego judicial al local del Congreso intentando convencer a los legisladores para dicho incremento, se repiten año a año como un rito inútil pues nunca se logra el cometido y difícilmente se hará en el fututo.

Más aún, el Tribunal Constitucional ha sido enfático al resolver la contienda competencial planteada por el Poder Judicial contra el Poder Ejecutivo para la aprobación del presupuesto en los mismos términos que presente el primero,

\footnotetext{
14 BAYLY LETTS, Andrés; PASQUEL RODRíGUEZ, Enrique. «¿Quién dijo que en Salem hubo brujas? La privatización del servicio de justicia: rompiendo el mito de la justicia estatal». Themis - Revista de Derecho $\mathrm{N}^{\circ} 46$. Pag. 18 .

15 BAyly LetTS, Andrés; PASQuel Rodríguez, Enrique. cit. pag. 18.
} 
Sergio Salas Villalobos - El Poder Judicial Peruano como objeto de estudio para la calidad de la democracia y administración de justicia en el Perú. Ventajas y dificultades

indicando que éste debe formular una política judicial de corto, mediano y largo plazo, en donde se defina el conjunto de criterios conforme a los cuales se orientará la organización judicial, identificando los fines generales y objetivos específicos. Agrega el Tribunal que el Poder Judicial debe evaluar los medios y recursos para alcanzar tales logros, determinando para ello las líneas de acción ${ }^{16}$.

Todo lo antes dicho, no es un capricho antojadizo del autor. Es más que conceptos de teoría económica. Es la interpretación del propio Tribunal Constitucional basado en tal teoría respecto de la forma de estructurar los recursos del Poder Judicial con un único propósito: orientar la organización judicial. Hasta el TC le ha dicho al Poder Judicial lo que debe hacer para ser eficiente. Manejarse organizacionalmente a través del control adecuado de sus recursos.

Casi después de diez años de aquella Sentencia, no se conoce ningún plan estratégico de políticas judiciales para el logro referido. No viene al caso gastar tiempo y esfuerzo para analizar ello, cuando es evidente; la falta de sentido organizacional de los agentes responsables a partir del propio gerenciamiento mediante el ocultamiento de información a los órganos de gobierno y directivos.

En cuanto a las tasas judiciales como medio de generación de ingresos propios, se puede decir que la sociedad es reacia a aceptar incrementos en sus montos. Si bien el noventa por ciento de lo que se recaude por tasas judiciales se destina a remuneraciones y solo el diez por ciento a bienes y servicios, tal distribución nos dice dos cosas: que el propio sistema judicial autofinancia las remuneraciones de los jueces, y que el monto destinado a bienes y servicios como recursos económicos de la organización, es insuficiente.

A ello cabe agregar que no existe un estudio técnico económico coherente, que justifique el monto de cada tasa judicial para cada caso concreto. Solo se miden las recaudaciones para empíricamente proyectar resultados de cada ejercicio económico anual. Es importante destacar que los servicios judiciales son por naturaleza costosos; y lo son por que deben serlo ${ }^{17}$. Están justificados por el valor intrínseco de operatividad de cada servicio judicial que se brinda. Sumado a ello, el costo del servicio también cumple un fin disuasivo para poder recurrir a los MARCs ${ }^{18}$. Finalmente, lo invertido en un

\footnotetext{
${ }^{16}$ Sentencia del Tribunal Constitucional 004-2004-CC/TC.

17 El sistema judicial norteamericano, por ejemplo, cuenta con los más altos costos para el acceso a los servicios judiciales de sus Tribunales.

18 Medios Alternativos de Solución de Conflictos.
} 
Sergio Salas Villalobos - El Poder Judicial Peruano como objeto de estudio para la calidad de la democracia y administración de justicia en el Perú. Ventajas y dificultades

juicio, económicamente no se considera como un gasto, sino como un costo de inversión que es recuperado al concluir a través de los costos y costas procesales.

Pero entonces, queda aún latente la duda. ¿Cómo se puede elevar los recursos económicos, sin incremento presupuestal ni de las tasas judiciales?

Mediante la tercerización de los servicios judiciales.

La monopolización de los servicios judiciales por el propio Poder Judicial, no hace sino incrementar su planilla de gastos de mantenimiento y operatividad. Ello, es sumamente costoso y sin valor de retorno, pues no están regulados por la ley del mercado de la oferta y la demanda, como en otros sistemas internacionales. No se trata de la privatización de la justicia, sino desprenderse de aquellos insumos que pueden ser encargados a un tercero con mejor know how y expertise en cada tema concreto, y que en la práctica constituye un sobrepeso de la economía judicial. Bajo principios de economía básicos, no es difícil concluir que tercerizando ciertos servicios, los costos disminuyen y por tanto el presupuesto ya asignado, puede tener otros fines útiles que satisfacer. Finalmente, al ser el Poder Judicial generador de tales insumos, obvio es que recabe un valor de comisión porcentual del precio que fije el mercado al servicio tercerizado, con lo cual se generan mayores ingresos como producto de eficiente calidad; más aún si no tiene competencia en el mercado.

Para demostrar la validez de estas premisas en la práctica, sugiero al lector visitar el siguiente link: http://www.ncsc.org/Services-and-Experts/ Technology-tools/Technology-vendors.aspx correspondiente al National Center for State Courts, el brazo técnico de las Cortes estatales de los Estados Unidos de Norteamérica al que nos hemos referido al describir el modelo del sistema corporativo o norteamericano. En dicho sitio encontrarán la relación de proveedores de los recursos tecnológicos que emplea este sistema para la prestación de los servicios judiciales, y son quienes los tercerizan con óptimos resultados. A tener en cuenta por cierto.

\section{Medios}

Un tercer y no por ello último componente del elemento de composición orgánica son los métodos de selección de los medios humanos. Para ser claros, las formas de selección de los jueces y su posterior designación en la función jurisdiccional. 
Sergio Salas Villalobos - El Poder Judicial Peruano como objeto de estudio para la calidad de la democracia y administración de justicia en el Perú. Ventajas y dificultades

El Perú, es el único país actualmente en los sistemas judiciales occidentales, donde la elección de jueces se hace a través de un órgano extra-poder. Los demás países han optado por una llamada fórmula mixta, en donde tal órgano realiza una preselección, pero su designación es finalmente política. Así, Linn HAMMERGREEN expresa: "El mecanismo preferido, pero no siempre adoptado, fue la creación de un consejo judicial, compuesto por representantes del propio Poder Judicial, los demás poderes del Estado, los colegios de abogados y a veces la sociedad civil. La mayoría de los países de la región adoptaron una variante de este mecanismo, usualmente para la preselección de candidatos, dejando la selección final a la corte suprema, el Poder Ejecutivo o el congreso"19.

Esto quiere decir que el común denominador de la forma de elegir a los jueces, es a través de una acción política por el Ejecutivo o Legislativo, según sea el caso, como en antaño. Al parecer, la fórmula parece invariable; sin embargo, con el mecanismo de pre-selección, las opciones quedan restringidas al criterio de los propios sistemas de justicia. Con ello, se advierte un primer y único filtro contra el manejo exclusivamente político del tema.

Como dijimos, el Perú no se alinea a esta fórmula mixta y se mantiene aislado en el sistema exclusivamente extra-poder a través del Consejo Nacional de la Magistratura cuyos componentes representan, en teoría, a la sociedad civil. Ello, para intentar adecuar la exigencia constitucional y confusa del artículo $138^{\circ}$ de nuestra carta magna ${ }^{20}$. Sin embargo el debate siempre ha estado propuesto, pero no se advierte la mínima intención de adecuar nuestro sistema a una forma constitucional y válidamente representativa que excluya la intervención política, ya que el contexto de la actual norma constitucional no es compatible con el diseño vigente.

Este diseño impone, en consecuencia, el método de la meritocracia, por el cual la elección de jueces, al estar excluido el componente político, obedece única y exclusivamente a la valoración del perfil profesional de los candidatos. Parte en consecuencia de la auto-postulación de los candidatos y no de la propuesta externa, ni del sistema mismo, ni de otros entes públicos. Siendo

\footnotetext{
${ }^{19}$ Hammegren, Linn. «Selección de jueces por voto popular en América Latina: ¿servirá el ejemplo de las elecciones estadounidenses?» En Aportes DPLF. Revista de la Fundación para el Debido Proceso Legal. Número 10. Año 3, Julio 2009. Nacional Endowment for Democracy. Washington D.C. U.S.A.

20 Artículo 138.- Administración de Justicia. Control difuso

La potestad de administrar justicia emana del pueblo y se ejerce por el Poder Judicial a través de sus órganos jerárquicos con arreglo a la Constitución y a las leyes. (El subrayado es nuestro)

La representación popular es a través del Poder Ejecutivo y Legislativo. El CNM ¿puede cumplir esta función?
} 
Sergio Salas Villalobos - El Poder Judicial Peruano como objeto de estudio para la calidad de la democracia y administración de justicia en el Perú. Ventajas y dificultades

ello así, es labor del Consejo determinar si las características de los postulantes responden a los estándares razonables de competitividad del cada vez más exigente mercado laboral en el quehacer jurídico. No se trata pues, que al final se nombren a aquellos que superaron las fases con los puntajes requeridos, sino que estos estén a la par o superen los estándares de calidad competitiva mencionados.

La tecnificación de este proceso luego de la verificación de los requisitos formales, comprende tres fases: prueba de conocimiento, evaluación curricular y entrevista personal. Cada una recibe un puntaje de acuerdo a parámetros pre-establecidos, de modo que logra ser juez aquel abogado que logró mayor puntaje de acuerdo al mínimo requerido en la escala valorativa. Sin embargo, no se percibe la apreciación del otro factor igualmente esencial además del conocimiento y capacidad jurídica; el perfil personal. ¿Tendrán los auto-postulantes claramente identificados los elementos que conforman el perfil del juez? ¿Estarán comprometidos a desarrollarlos en el ejercicio de sus funciones judiciales? ¿Se identifican con los valores del asociacionismo judicial de la corriente española o la institucionalidad judicial del juez italiano Giovanni Falcone? Son algunas no pocas interrogantes que este sistema nos deja.

La fase formativa es fundamental para responder estas preguntas. Sin embargo, ese es un tema excluyente de lo que se trata en este trabajo. Tanto la formación académica pre y post grado -a través de la Academia de la Magistratura- son los elementos sustanciales para identificar el perfil adecuado a lo que por juez independiente se entiende. Tarea igualmente pendiente.

Por último, queda el tema de la estabilidad de los jueces en el cargo. De acuerdo a la Constitución, todos los jueces titulares de la República, deben someterse a un proceso de ratificación por el $\mathrm{CNM}$ cada siete $a_{n} \mathrm{~s}^{21}$, de manera obligatoria y sin excepción.

Sin duda, una de las garantías de la adecuada y correcta impartición de justicia, es que la solución de los conflictos esté a cargo de jueces titulares; por que ellos han sido precisamente seleccionados para tal función. Por tanto, para que ello sea eficaz, se necesita que tales jueces estén a su vez rodeados de todos los medios que garanticen su estabilidad en el cargo. Es un razonamiento lógico.

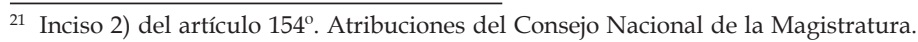


Sergio Salas Villalobos - El Poder Judicial Peruano como objeto de estudio para la calidad de la democracia y administración de justicia en el Perú. Ventajas y dificultades

No obstante, no dejan de ser funcionarios públicos, aunque especiales, sujetos también a ciertos mecanismos de control de idoneidad. Nuestro sistema considera que el apropiado es el de las ratificaciones de los jueces titulares cada siete años. Reiteramos: el sistema lo considera apropiado, pero ¿en realidad lo es?

Diversos movimientos y declaraciones institucionales han reclamado -sin éxito por cierto- la modificación constitucional que elimine el proceso de ratificaciones porque, en efecto, objetivamente es inadecuado ${ }^{22}$.

El proceso de ratificaciones, distrae al Magistrado a la mitad de ese periodo para tratar de cumplir con todos los requisitos que el mismo exige. Es similar al de acceso a la judicatura, eminentemente técnico y sujeto a una tabla porcentual; de manera que el Juez que no consigue el puntaje necesario, es separado de la mal llamada carrera judicial ${ }^{23}$. Se dice que este método es objetivo, por cuanto el Consejo se ciñe únicamente a la apreciación de idoneidad de manera técnica. En teoría, no habría forma de introducir por parte de los consejeros juicios de valor personales en la calificación apreciativa, lo que tornaría el método en subjetivo. Sin embargo, basta apreciar las resoluciones respecto de los jueces Miguel Torres Méndez ${ }^{24}$-que fue la primera con motivación expresa luego del caso Álvarez Guillén- y Niquén Peralta ${ }^{25}$, entre otras, para dudar de la validez de esa premisa.

La experiencia nos indica entonces, que este modelo técnico, tampoco es garantía plena de estabilidad del cargo titular del juez.

La falta de adecuada estructura organizacional de nuestro sistema judicial, ha hecho que este cada vez sea más grande; es decir, bajo el otro mito de la sobrecarga judicial, se crean más órganos judiciales para eliminarla, lo que nunca se ha conseguido y dudamos se conseguirá si se sigue con este modelo improvisado. Ello, obliga a que se creen más plazas de jueces, por lo que los procesos de acceso a la judicatura, se tornan permanentes. Este proceso a la vez que se incrementa en oportunidades, también lo hace en plazas. En tanto

\footnotetext{
${ }^{22}$ En tanto no se eleve el rango de legitimación social del Juez peruano, resulta contraproducente esta corriente, en tanto puede ser usado como herramienta de control de poder por el poder político del Ejecutivo y Legislativo.

23 Nuestro sistema piramidal jerarquizado y la diferencial remunerativa de los jueces, ha convertido la carrera judicial en una competencia para ver quien llega más alto en la pirámide símbolo de poder, y de paso mejorar sus escalas salariales. Este modelo, difiere de horizontalismo europeo, que adapta el sistema de bonos que sin duda incentiva a los jueces dedicados a la aportación de logros y al real ejercicio de las funciones que realizan.

24 Resolución 001-2006-PCNM.

25 Resoluciones 191-2012-PCNM y 384-2012-PCNM.
} 
Sergio Salas Villalobos - El Poder Judicial Peruano como objeto de estudio para la calidad de la democracia y administración de justicia en el Perú. Ventajas y dificultades

ello ocurre, y estando a la promoción constante de los jueces en aquellos órganos transitorios, crean la generación de hasta otras dos clases de jueces, los provisionales y los supernumerarios.

Ahora bien, estando a que los primeros aún están en el proceso de integración de la antigua carrera judicial por la vigente, su plaza original no es la de Juez, sino Auxiliar Jurisdiccional. No siendo por ende juez titular de ninguna jerarquía -no obstante desempeñar la misma labor-, sin embargo no está sujeto a ratificación por el CNM. Tampoco lo están los jueces suplentes o supernumerarios que no ocupan plaza titular ${ }^{26}$.

Este sistema, en consecuencia, traslada la garantía de la inamovilidad en el cargo de juez del titular al provisional y supernumerario. Mientras los primeros son los menos estables en el cargo, los segundos en la práctica poseen mayor estabilidad. Comprobación irrefutable de lo inapropiado del sistema peruano.

Por último, queda el tema de la capacitación constante del Juez. Este modelo ambiguo e híbrido, exige que el Juez se capacite constantemente de acuerdo a las exigencias del Derecho moderno y a la cada vez mayor influencia de las teorías de la argumentación y la del razonamiento jurídico. En tal sentido, es requisito indispensable para mantenerse en el cargo, que el juez peruano acredite ante el CNM su participación en la mayor cantidad de cursos de especialización jurídica y, como consecuencia de ello, posea la mayor cantidad también de títulos de acreditación de especialidad.

Para nadie es una novedad que la oferta académica post grado no solo ha crecido en el Perú -fiel reflejo de la corriente española- sino que, si bien la oferta es abundante, son pocos los productos académicos realmente que superan los márgenes de calidad profesional. El producto en sí, se ha convertido en una finalidad comercial de las instituciones académicas que lo ofrecen, al margen de lo que realmente puedan entregar en resultados a los discentes. Ello ha tornado como costumbre imperante por el sistema, el seguimiento de maestrías en distintos países, sobre todo de Europa, retornando luego con un deslumbrante título refrendado por una Universidad extranjera, lo que en apariencia denota alta capacitación. Sin embargo, en dichos lugares ocurre lo mismo que en el Perú, es mucha la oferta y poca la calidad comprobada, solo que desconociéndose esta, se resalta su título.

\footnotetext{
${ }^{26}$ Solo la distinguida jurista Marianella LEDESMA N., desempeña una plaza titular como Juez supernumerario de la Corte Superior de Lima.
} 
Sergio Salas Villalobos - El Poder Judicial Peruano como objeto de estudio para la calidad de la democracia y administración de justicia en el Perú. Ventajas y dificultades

A lo que nos referimos es que el sistema continúa distrayendo al Magistrado, quien debe buscar las mejores ofertas del mercado académico, para seguir sumando puntajes calificatorios al momento de su ratificación. Lo que se pueda asimilar, pasa pues a un segundo plano. Al parecer, el sistema descuida la atención en la Academia de la Magistratura, que igualmente posee rango constitucional y cuyas finalidades son la de formar aspirantes a jueces y brindar capacitación constante a los jueces en actividad ${ }^{27}$.

Sin embargo, la atención del sistema hacia la Academia es mínima. Es esta institución la única que debe tener la calificación exclusiva de la capacitación acreditativa de los jueces. Asimismo, debe ser el factor referencial para que el CNM diseñe sus métodos de acceso; cosa que no ocurre. El Estado debe adecuar el marco normativo de la educación profesional, para que la AMAG pueda otorgar igualmente títulos a nombre de la Nación a los jueces en su capacitación constante. Ello, ocurre en casi todas las escuelas judiciales de América Latina.

Hay que tener en cuenta que la función primordial del juez, es la de dedicarse a su despacho judicial. Por tanto, la labor formativa de capacitación debe estar garantizada por el Estado de manera adecuada y razonable, de forma que no perjudique la atención del despacho judicial. El Estado debe capacitar al juez y no dejar que el juez agote esfuerzos en ello.

\section{Ideologías como Doctrina judicial}

Por último, queda el factor ideológico. Por ideología entendemos una serie de pensamientos formados en base a la concurrencia de principios que sostienen una creencia válidamente comprobada, la cual aceptamos como cierta y cuya finalidad es el logro de determinado objetivo.

Sin embargo, esta acepción cobra mayor vigor cuando ese objetivo se desarrolla en un escenario social común, y que mayormente busca la integración de sus componentes. Las ideologías son de diversa índole, desde ideas políticas, religiosas, dogmáticas, prácticas, económicas, etc.

Ahora bien, tales ideologías deben estar debidamente comprobadas mediante la aplicación de elementos que se transforman en reglas a seguir y constituyen

\footnotetext{
27 Constitución Política. Artículo 151.- Academia de la Magistratura

La Academia de la Magistratura, que forma parte del Poder Judicial, se encarga de la formación y capacitación de jueces y fiscales en todos sus niveles, para los efectos de su selección. Es requisito para el ascenso la aprobación de los estudios especiales que requiera dicha Academia.
} 
Sergio Salas Villalobos - El Poder Judicial Peruano como objeto de estudio para la calidad de la democracia y administración de justicia en el Perú. Ventajas y dificultades

sus principales pilares. Los métodos interpretativos de las ideologías, a su turno formarán los llamados paradigmas.

Cuando estas ideologías son capaces de formar paradigmas, estaremos frente al nacimiento de las Doctrinas, que es el producto del razonamiento científico de las ideas y su comprobación práctica. Así nacieron las doctrinas políticas del federalismo, capitalismo, comunismo, socialismo, etc.; o las jurídicas del jusnaturalismo, positivismo, neoconstitucionalismo, etc.

Pretender que se desarrollen doctrinas judiciales, sin duda es una meta sumamente ambiciosa. Implicaría otorgarle rango de ciencia a la investigación y ordenamiento judicial. Que se tenga conocimiento, aún no se ha podido ordenar o compilar disciplinariamente, la abundante temática que comprende el Derecho Judicial; ello, por ser una corriente realmente nueva en el Derecho. Comúnmente los juristas se concentraron en el Derecho Procesal y nada más, perdiendo de vista la manera en que los jueces desarrollan en la práctica tal disciplina jurídica. Es precisamente con la evolución de las teorías de la argumentación y del razonamiento jurídico, que se advierte interés por la forma en que los jueces aplican las normas y resuelven los conflictos sociales.

Tal interés por su lado, no se queda solo en la parte interpretativa de ambas teorías, sino que necesariamente se interiorizan con todos los aspectos que rodean la actividad del juez, más allá del proceso. Así, de a pocos se va entrando en un mundo en que el Derecho como práctica, queda suspendido o supeditado a toda una realidad complementaria: el quehacer judicial. Desde la forma de elección de los jueces, hasta el diseño de los despachos judiciales, pasando por los servicios que surten al proceso judicial mismo.

Se advierten hasta tres factores que obligan a diseñar ideas o pensamientos propios del quehacer judicial. El primero, la gran transformación social, política y económica que experimentó el mundo a partir de los años noventa. El avance de la tecnología, la redefinición de la nueva gestión pública, las modernas estructuras de Estado, la capacitación intelectual en un mundo agresivamente competitivo; es decir, el fenómeno de la globalización ya no como fenómeno económico, sino trascendido a los terrenos sociales y políticos. Ello obliga a que los componentes del Poder Judicial -los juecesestén en este nivel de nuevas conductas sociales.

Un segundo factor, es el escenario socio-político de los sistemas judiciales institucionalistas ya tratados, en los cuales la existencia de órganos constitucionales autónomos tienen mayor o menor incidencia sobre los tres poderes clásicos del Estado; lo que en teoría política se denomina el control 
Sergio Salas Villalobos - El Poder Judicial Peruano como objeto de estudio para la calidad de la democracia y administración de justicia en el Perú. Ventajas y dificultades

constitucional del poder político. Implica el control interorgánico o vertical como lo trata Loewenstein al considerar que funciona entre los diversos detentadores de poder que cooperan en la gestión estatal ${ }^{28}$. Es evidente que a mayor intervención interogánica o extrapoder, mayor defensa institucional, lo que obliga a los jueces a establecer políticas igualmente institucionales que sean capaces de identificar, desarrollar, planificar y ejecutar. Este mecanismo de defensa institucional intraorgánica, sin duda distrae mayormente la labor del juez, ya que además de cumplir con las exigencias académico competitivas del sistema para su supervivencia en el mismo, debe preocuparse también de su autogobierno y de su autogestión; lo que no ocurre en los sistemas parlamentaristas y corporativo. Si bien ello puede beneficiar a la formulación de políticas é ideologías judiciales, no obstante empaña grandemente su función jurisdiccional que le es propia.

Un último elemento derivado del anterior, es la necesidad imperiosa que los jueces consoliden los procesos de transformación sistémico institucional; mal llamada reforma judicial. Si bien en la práctica material esta transformación es una reforma, no obstante nuestro sistema peruano es opuesto a dicha calificación. Precisamente, su uso político durante la época republicana como pretexto para cambiar jueces proclives al favor político, ha deslegitimado el término, a tal extremo que el único intento serio en su orígenes derivó en un copamiento masivo del Poder Judicial entre los años 1997 y 2000. Tan es así, que luego de dicho proceso no se ha vuelto a mencionar más ese término por los propios representantes de la judicatura, mencionando en su reemplazo el proceso de modernización. Es cierto que en los últimos años se advierte importantes impulsos desde el interior del propio sistema para entender la manera como lograr este proceso de transformación. Existe una mayor apertura de los jueces en todos los niveles. Sin embargo, también se nota lógico recelo de abrir aún más el portal institucional para la cooperación externa; la experiencia histórica, aconseja prudencia.

Consecuentemente, la concurrencia conjunta de estos elementos, sin duda deriven en la formulación de ideas para el diseño de una doctrina judicial basada en principios constitucionales y democráticos que sustenten la fortaleza institucional de este Poder del Estado. Estas ideologías si bien se aprecian formadas desde el interior, aún se advierten carentes de metodologías que las orienten para el fin propuesto. En virtud de ello, tales

\footnotetext{
${ }^{28}$ Citado por Huerta OCHOA, Carla. «Mecanismos constitucionales para el control del poder político». México, UNAM - IIJ, 2001, pp.21 - 22. GARCíA OLIVO, Miguel Angel, «Instrumentos de control constitucional del poder político Ejecutivo». En Matices, Revista de Posgrado. Volumen 5, Nº 12. 2010, México; p. 177.
} 
Sergio Salas Villalobos - El Poder Judicial Peruano como objeto de estudio para la calidad de la democracia y administración de justicia en el Perú. Ventajas y dificultades

metodologías deben ser colectivas dentro del mismo sistema, notándose que a través del asociacionismo judicial -importante ideología- serios esfuerzos participativos de los jueces. Ejemplo de ello, es la Asociación de Jueces para la Justicia y la Democracia - JUSDEM, donde hay que destacar parte de la declaración de principios de esta asociación -, cuando precisamente resalta la necesidad de: "... examinar críticamente la situación del respeto a la Constitución y principalmente evaluar la situación del Poder Judicial como órgano controlador de los poderes del Estado, a fin de contribuir a una eficaz mejora del ámbito judicial, para ello no solo es necesario detectar deficiencias y proponer mejoras, si no también , tomar conciencia de que, aún tras la transformación que viene experimentando la administración de justicia en nuestro país, existe en la sociedad un extendido estado de opinión que refleja una profunda insatisfacción con el funcionamiento de esta y que afecta negativamente a la confianza del pueblo peruano en nuestro sistema de administración de justicia, que debe revertirse" 29 .

Tal expresión colectiva bajo la forma de asociacionismo judicial, sitúa a quienes la componen, en el nuevo perfil ideológico del juez peruano bajo una perspectiva de participación y de interés propio. Ante la exigencia del sistema de contar con jueces con participación más activa, este perfil denota claramente un fuerte impulso interno que garantiza de alguna manera la generación de liderazgos institucionales a los que deben sumarse los representantes de este poder del Estado.

Corresponde a los propios actores judiciales empujados por la exigencia social, determinar los mejores métodos para dar formas a las ideas sobrevivientes destinadas a la generación de una doctrina judicial que refuerce el poder del Poder Judicial por sus principios y por sí mismo. Hablar de la nueva función política del juez peruano, orientada en esta forma, no suena entonces tan desproporcionada. A fin de cuentas, de lo que se trata, entendemos, es revertir el estado de de la apolitización del juez como doctrina imperante en la época republicana hasta los años ochenta, como nos enseñó Pasara y al que hemos referido anteriormente en este breve ensayo.

\section{A MANERA DE CONCLUSIÓN}

De lo expuesto, consideramos que si bien el sistema judicial peruano ha evolucionado con mayor notoriedad a partir del año 2001 sobre todo en su aspecto institucional, no obstante y a pesar de su posición expectante en la región latinoamericana, aún tiene mucho camino por recorrer.

\footnotetext{
${ }^{29}$ Información institucional tomada de la fuente http://www.jusdem.org.pe/institucional.html
} 
Sergio Salas Villalobos - El Poder Judicial Peruano como objeto de estudio para la calidad de la democracia y administración de justicia en el Perú. Ventajas y dificultades

Sin embargo, la extensión del mismo puede verse notoriamente reducida si desde el propio Estado se asume la responsabilidad de que para la estabilidad democrática como garantía de inversión y desarrollo socio-económico, con inclusión y seguridad ciudadana, es indispensable brindar atención prioritaria de una vez para dar solución a las deficiencias que presente el sistema. Considerar que el sistema de justicia en el país es un asunto que solo compete a los jueces es un grave error. Por el diseño del mismo, son sus principales protagonistas pero no los únicos responsables de su legitimación. Todos los actores y componentes políticos, económicos, sociales, académicos, profesionales en general, deben coadyuvar al bien común de reforzar el sistema de justicia.

Ello implicará cambios normativos en cuanto al diseño orgánico estructural del sistema, readaptación de los mecanismos de la carrera judicial, revisión de los métodos de acceso a la judicatura y de control jurisdiccional, entrenamiento formativo de los jueces, participación ciudadana responsable en el quehacer judicial, transformación de la conducta ética de los abogados a partir de sus gremios; en fin, notables y grandes cambios que pueden ser paulatinos pero articulados.

El esfuerzo que se advierte desde el interior del sistema, no se ve reflejado ni interorgánicamente, ni por la sociedad. Sin duda, la falta de información desde el portal institucional, no ayuda a ello. El recordado jurista SANTISTEVAN DE NORIEGA precisamente desde su función de Defensor del Pueblo en la etapa de reconstrucción democrática en el Perú y posterior a ella, reiteradamente se refirió en la necesidad de establecer la promoción de la transparencia y acceso a la información pública teniendo en cuenta las experiencias y estándares internacionales para ello ${ }^{30}$. Nada más acertado.

Por su parte, el asociacionismo judicial que intenta cubrir el espacio vacío interior, aún es insuficiente, y lo seguirá siendo en la medida que no se refuercen las alianzas estratégicas con la sociedad en general.

En suma, el actual sistema implica una garantía relativa para calificar la calidad democrática de la administración de justicia en el Perú, la cual sin duda se orienta a una mejora sustancial; pero para ello, es indispensable repensar el actual modelo integral y formar las ideologías apropiadas para el cambio positivo sustancial. A fin de cuentas, no se puede esperar un proceso de transformación, si no se cree en él.

${ }^{30} 1^{\text {a }}$ Conferencia Nacional sobre Acceso a la Información. Lima, 29 y 30 de Septiembre de 2008; Instituto Prensa y Sociedad - IPYS. 
Sergio Salas Villalobos - El Poder Judicial Peruano como objeto de estudio para la calidad de la democracia y administración de justicia en el Perú. Ventajas y dificultades

\section{REFERENCIAS BIBLIOGRÁFICAS}

BAYLY LETTS, Andrés; Pasquel Rodríguez, Enrique. ¿Quién dijo que en Salem hubo brujas? La privatización del servicio de justicia: rompiendo el mito de la justicia estatal. Themis - Revista de Derecho $N^{\circ} 46$.

GARCía BELAÚNDE, Domingo. Problemas sobre el gobierno y la Administración del Poder Judicial. Publicado en: La Justicia Mexicana hacia el siglo XXI por la Universidad Nacional Autónoma de México y el Senado de la República LVI Legislatura.

GARCía Olivo, Miguel Angel, Instrumentos de control constitucional del poder político Ejecutivo. En: Matices, Revista de Posgrado. Volumen 5, $\mathrm{N}^{\circ}$ 12. 2010, México.

HAMMEGREN, Linn. Selección de jueces por voto popular en América Latina: ¿servirá el ejemplo de las elecciones estadounidenses? En: Aportes DPLF. Revista de la Fundación para el Debido Proceso Legal. Número 10. Año 3, Julio 2009. Nacional Endowment for Democracy. Washington D.C. U.S.A.

Huerta OchOA, Carla. Mecanismos constitucionales para el control del poder político. México, UNAM - IIJ, 2001.

KRUGMAN, Paul; Wells, Robin. Macroeconomía: introducción a la economía. [versión española traducida por Gotzone Pérez Apilanez. Editorial Reverté S.A. Barcelona, España. 2006.

MORLINO, Leonardo and Diamond, Larry. Assessing the Quality of Democracy. The Johns Hopkins University Press and the National Endowment for Democracy. Baltimore, Maryland. United States of America. 2005.

PÁsARA, Luis. Justicia y Poder en el Perú. Centro de Estudios de Derecho y Sociedad. Perú. 1982. 